\title{
Sulfonamide Directivity Enables Ni-Catalyzed 1,2-Diarylation of Diverse Alkenyl Amines
}

\author{
Omar Apolinar ${ }^{[a]}$, Van T. Tran ${ }^{[a]}$, Michael A. Schmidt $t^{[b]}$, Joseph Derosa ${ }^{[a]}$, and Keary M. Engle ${ }^{[a] *}$
}

\begin{abstract}
Diarylation of alkenyl sulfonamides with aryl iodides and aryl boronic esters under nickel catalysis is reported. The developed method tolerates coupling partners with disparate electronic properties and substitution patterns. 1,2- and 1,1Disubstituted alkenes, as well as alkenes distal from the directing group, are all accommodated. Control experiments are consistent with a $\mathrm{N}-\mathrm{Ni}$ coordination mode of the directing group, which stands in contrast to earlier reports on amide-directed 1,2-diarylation that involve carbonyl coordination. The synthetic utility of the method arises from the dual function of the sulfonamide as both a directing group and masked amine nucleophile. This is highlighted by various product diversifications where complex amine compounds are synthesized in a two-step sequence of $\mathrm{N}$-functionalization and deprotection of the sulfonyl group.
\end{abstract}

Forging contiguous $\mathrm{C}-\mathrm{C}$ bonds through 1,2dicarbofunctionalization of alkenes, also referred to as conjunctive cross-coupling, has blossomed into a vibrant area of catalysis that leverages the unique reactivity of diverse transition metals, including $\mathrm{Pd}, \mathrm{Ni}, \mathrm{Co}, \mathrm{Cu}$, and Fe. ${ }^{[1 \mathrm{a}-\mathrm{b}]}$ In this context, nickel provides unique advantages compared to other transition metals, such as palladium, by having a higher

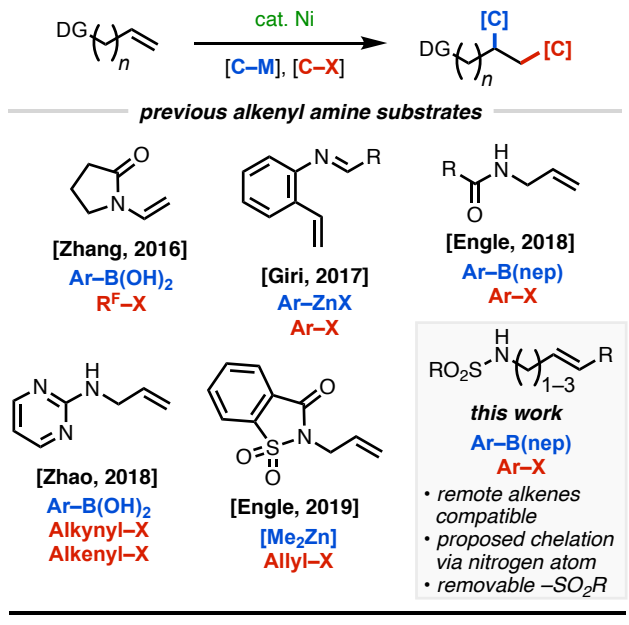

Scheme 1. Previous reports and synopsis of new findings.

[a] O. Apolinar, V. T. Tran, Dr. J. Derosa, Prof. K. M. Engle Department of Chemistry

The Scripps Research Institute

10550 North Torrey Pines Road, La Jolla, California 92037 (USA)

E-mail: keary@scripps.edu

[b] Dr. M. A. Schmidt

Chemical Process Development

Bristol Myers Squibb

One Squibb Drive, New Brunswick, New Jersey 08903 (USA)

Supporting information for this article is given via a link at the end of the document. propensity toward oxidative addition and 1,2-migratory insertion steps while being more resilient towards $\beta$-hydride elimination. ${ }^{[1 \mathrm{c}]}$ 1,2-Dicarbofunctionalization of alkenyl amine substrates, wherein a protected amine directs key steps in the catalytic cycle, is an attractive approach for selectivity control and offers rapid entry to functionalized alkyl amine product libraries. 1,2-(Fluoroalkyl)arylation and 1,2-diarylation of electronically activated enamides and ortho-vinyl aniline derivatives have been reported by Zhang ${ }^{[2 a]}$ and Giri ${ }^{[2 b]}$, respectively (Scheme 1 ). More recently the use of a non-

Table 1. Optimization of 1,2-diarylation reaction. ${ }^{\text {[a] }}$

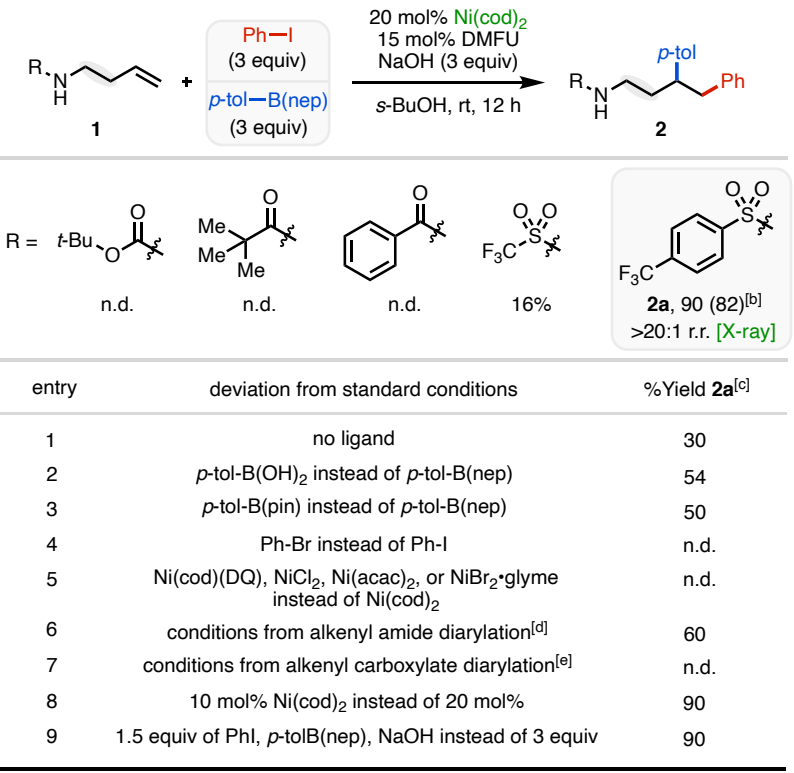

[a] Reaction conditions: 1a $(0.1 \mathrm{mmol}), 0.2 \mathrm{M} \mathrm{s}-\mathrm{BuOH}$. [b] Values in parentheses are isolated yields. [c] Percentage yield by ${ }^{1} \mathrm{H}$ NMR using $\mathrm{CH}_{2} \mathrm{Br}_{2}$ as the internal standard; n.d. = not detected. [d] Reaction conditions: $15 \mathrm{~mol} \% \mathrm{Ni}(\mathrm{cod})_{2}, 15 \mathrm{~mol} \%$ dimethylfumarate, 1.5 equiv $\mathrm{Arl}$, 1.5 equiv $\mathrm{ArB}(\mathrm{nep}), 2$ equiv $\mathrm{NaOH}, 0.2 \mathrm{M} i-\mathrm{BuOH}$ at r.t. [e] Reaction conditions: 15 mol\% Ni(cod)2, 2 equiv Arl, 2 equiv $\mathrm{ArB}($ nep), 2 equiv $\mathrm{NaOH}$, $0.1 \mathrm{M} \mathrm{s}-\mathrm{BuOH}$ at $50{ }^{\circ} \mathrm{C}$.

removable pyrimidyl auxiliary that facilitates the 1,2dicarbofunctionalization of non-conjugated terminal alkenes via coordination of $\mathrm{Ni}$ with a $\mathrm{N}\left(\mathrm{sp}^{2}\right)$ atom center was reported by Zhao and coworkers. ${ }^{[2 e]}$ Our group has reported the 1,2diarylation and 1,2-allylmethylation of simple alkenyl amides and $\mathrm{N}$-allyl heterocycles, respectively. ${ }^{[3 a-b]} \mathrm{Ni}$-catalyzed conjunctive cross-couplings of various classes of nonconjugated alkenes have been reported by other research groups via different mechanistic paradigms. ${ }^{[4]}$ This progress notwithstanding, significant limitations remain in this family of transformations. In particular, existing methods are incompatible with homoallyl and bis-homoallyl amines as well as internal alkenyl amine substrates. Moreover, the directing groups employed in earlier reports are synthetically restrictive in that they cannot be directly employed in further functionalization. The goal of the present study was to identify an amine-based directing group capable of promoting 1,2diarylation of remote, highly substituted alkenes and engaging in diverse downstream $\mathrm{N}$-functionalization chemistry, which 
would allow alkenyl amines to act as linchpins in modular synthesis. To this end, herein we report the identification of sulfonamides as uniquely effective and versatile $e^{[5,6]}$ directing groups in 1,2-diarylation of alkenes under nickel/dimethyl fumarate (DMFU) catalysis. ${ }^{[7]}$

To commence the study, we selected iodobenzene and 4-tolylboronic acid neopentyl glycol ester ( $p$-tolB(nep)) as model coupling partners and systematically surveyed homoallyl amine substrates bearing different protecting groups. Carbonyl groups that were previously found to direct 1,2-diarylation of allylamine substrates, namely Boc-, Piv-, and $\mathrm{Bz}-$, were ineffective in this case with a more distal alkene. We next turned to sulfonyl protecting groups ${ }^{[6]}$ with the hypothesis that in this case, the nickel catalyst may bind the sulfonamide through nitrogen. Gratifyingly, triflyl-protected homoallyl amine gave the desired product, albeit in low yield. Moving to a less electron-withdrawing aryl sulfonyl group provided 1,2diarylated product $2 \mathrm{a}$ in excellent yield and regioselectivity, and its connectivity was confirmed by single-crystal X-ray diffraction. While various aryl sulfonamide directing groups

Table 2. Electrophile, nucleophile, sulfonamide and alkene scope. ${ }^{[a]}$ were similarly effective (vide infra), the 4-(trifluoromethyl)phenyl group provided a convenient ${ }^{19} \mathrm{~F}$ NMR handle for reaction analysis and was employed for much of the ensuing work. The absence of DMFU and employment of the aryl boronic acid and pinacol ester resulted in diminished yields (Entries 1-3). Bromobenzene was unreactive as an electrophile, and other nickel precatalysts, such as $\mathrm{Ni}(\mathrm{cod})(\mathrm{DQ}), \quad \mathrm{NiCl}_{2}, \mathrm{Ni}(\mathrm{acac})_{2}$, and $\mathrm{NiBr}_{2} \bullet$ glyme, were ineffective (Entries 4-5). Under previously published reaction conditions for diarylation of alkenyl amide substrates, lower yield was obtained (Entry 6). No diarylation was observed under conditions for alkenyl carboxylate substrates (Entry 7). ${ }^{[3 a, 4 i]}$ While excellent yields were obtained when lower catalyst loading or equivalents of coupling partners and base were used upon the standard substrate (Entry 8-9), across other examples, higher loading and equivalents gave improved yields.

Next, the scope of electrophilic and nucleophilic aryl coupling partners was investigated (Table 2). Electronwithdrawing groups at the para position of the aryl iodides<smiles>[R]/C=C\CCN[SH](=O)=O</smiles>

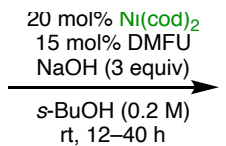<smiles>[Y]C([AlH2])C([Y])([Y])CCN[SH2]([3H])=O</smiles>

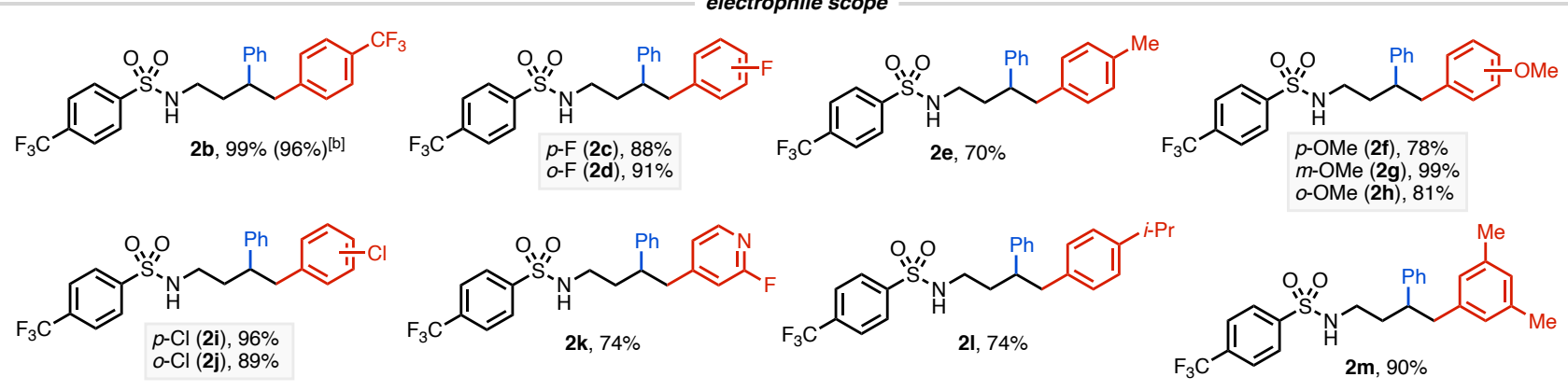<smiles>COc1ccc(C(CCNS(=O)(=O)c2ccc(C(F)(F)F)cc2)CC(Cc2ccccc2)c2ccc(C(F)(F)F)cc2)cc1</smiles><smiles>O=[N+]([O-])c1ccc(C(CCNS(=O)(=O)c2ccc(C(F)(F)F)cc2)Cc2ccccc2)cc1</smiles><smiles>O=S(=O)(NCCC(Cc1ccccc1)c1ccc(Oc2ccccc2)cc1)c1ccc(F)cc1</smiles><smiles>CC(=O)c1cccc(C(CCNS(=O)(=O)c2ccc(C(F)(F)F)cc2)Cc2ccccc2)c1</smiles>
2s, $89 \%$

2t, $91 \%$<smiles>C=CCCNS(=O)(=O)c1ccc(N(C)CCC(=O)NS(=O)(=O)c2ccc(C(F)(F)F)cc2)cc1</smiles> 
afforded the highest product yields $(\mathbf{2} \mathbf{b}-\mathbf{c}, \mathbf{2} \mathbf{i})$, and the product yield decreased with electron-neutral and -donating groups $(\mathbf{2 e}-\mathbf{f}, \mathbf{2 I})$. It is worth noting that product $\mathbf{2 b}$ was synthesized in an excellent yield on a larger scale ( $1 \mathrm{mmol}, 0.48 \mathrm{~g}$ isolated). Electron-withdrawing groups on the meta position of the aryl iodides gave no 1,2-diarylated product; however, electrondonating groups $(\mathbf{2 g}, \mathbf{2 m})$ gave 1,2-diarylation in excellent yields. Ortho-substituted electron-withdrawing or donating groups on the aryl iodide had little effect on the product yield in comparison to the para-substituted examples $(\mathbf{2 d}, \mathbf{2} \mathbf{h}, \mathbf{2 j})$. Consistent with the previously discussed results, electrondeficient 2-fluoro-4-iodopyridine gave good yield (2k). With regards to the nucleophile scope, no apparent trend is observed. Electron-withdrawing and weakly electron-donating groups on the para position (2n-o, 2s) gave very good yields. Product yields greatly varied with the use of electron-donating groups on the para position ranging from moderate to excellent yields $(\mathbf{2 r}, \mathbf{2 u}-\mathbf{v})$. Aryl boronic esters with electron withdrawing groups on the meta and ortho positions $(2 \mathbf{p}, 2 \mathbf{2 q}, \mathbf{2 t}, \mathbf{2 w})$ resulted in moderate to excellent yields as well.

Next, we varied the aryl sulfonyl group by substitution of the trifluoromethyl moiety at the para-position and observed good to excellent yields $(\mathbf{2} \mathbf{x}-\mathbf{z})$. Mesyl (Ms) protected homoallyl amine $2 \mathrm{aa}$ is a competent substrate under the reaction conditions. However, product was not detected in the case of a nosyl protecting group, which we attribute to the potential inhibitory effect of nitro groups on $\mathrm{Ni}$ catalyst activity. ${ }^{[8]}$ We then examined alkene substrates that are typically challenging in 1,2-diarylation. Pleasingly, (Z)- and (E)internal alkenes were well tolerated under the optimized reaction conditions. Diarylated product from a (Z)-alkene was obtained in good yield and as a single diastereomer, as confirmed by single-crystal X-ray diffraction $(\mathbf{t}-\mathbf{2 a b})$. The $(E)$ alkene was diarylated in the same fashion, but in a higher yield $( \pm-2 a c)$. In addition, a 1,1-disubstituted terminal alkene was found to work moderately well under the reaction conditions (2ad). With substitution at the a-position, no conversion was observed.

In a series of control experiments, both homoallyl aryl sulfonate 10 and $\mathrm{N}$-methylated sulfonamide $1 \mathrm{p}$ were subjected to the optimized conditions, which resulted in no product formation (Scheme 2A). This indicates that the $\mathrm{N}-\mathrm{H}$ moiety is important in the transformation. While we were successful in developing a remote alkene 1,2-diarylation reaction, we were
A. control experiments

$$
\begin{gathered}
\mathrm{Ar}= \\
p-\mathrm{CF}_{3} \mathrm{C}_{6} \mathrm{H}_{4}
\end{gathered}
$$

B. tether length effects

$$
\begin{array}{ll} 
& n=1(\mathbf{2 a f}): 68 \%, 7: 1 \text { r.r. } \\
\mathrm{ArO}_{2} \mathrm{~S} & -\mathrm{N}_{n}(\mathbf{2 a}): 82 \%,>20: 1 \text { r.r. } \\
n=3(\mathbf{2 a g}): 82 \%,>20: 1 \text { r.r. } & n=4:(2 \mathrm{ah}): \text { n.d. }
\end{array}
$$

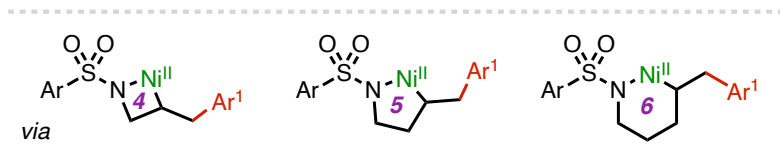

C. proposed catalytic cycle

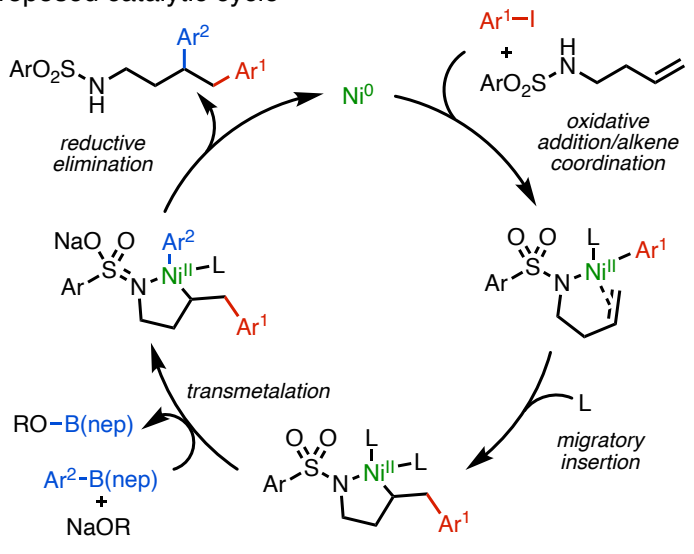

Scheme 2. (A) Control experiments to test sulfonamide and nitrogen importance. (B) Tether length effects on 1,2-diarylation. (C) Proposed catalytic cycle having directing group with X-type coordination upon migratory insertion.

curious about the effect of alkene distance on reactivity (Scheme 2B). When aryl sulfonyl protected allyl amine was subjected to the reaction conditions, diarylated product was obtained in a lower yield and as a 7:1 mixture of regioisomers (2af). Reaction of aryl sulfonyl protected pentenyl amine

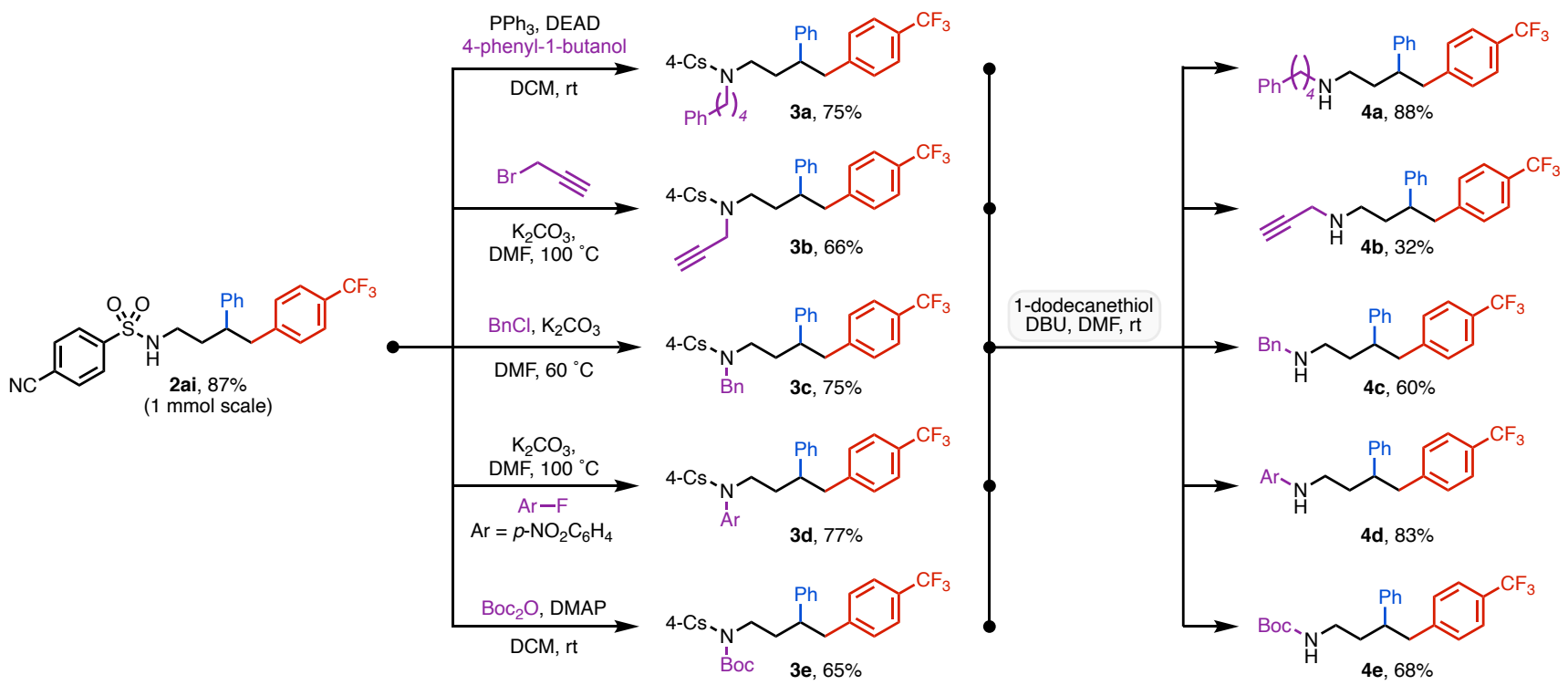

Scheme 3. Diversification of 1,2-diarylated products as a linchpin technology. Percentages represent isolated yields. 
unexpectedly gave the diarylated product in a good yield with excellent regioselectivity (2ag). Extension of the alkenyl chain to aryl sulfonyl protected hexenyl amine gave no product. We hypothesize that these alkenyl amine substrates go through 46-membered nickelacycles, where a 7-membered nickelacycle is unfavorable.

Although this reaction may proceed via a $\mathrm{N}-\mathrm{Ni}$ coordination mode, ${ }^{[9]}$ the general catalytic cycle likely follows a similar mechanism as that of alkenyl amide and carboxylate diarylation (Scheme $2 \mathrm{C}){ }^{[3 a, 4 i]}$ The proposed catalytic cycle starts with nickel undergoing oxidative addition into the aryliodide bond, followed by alkene coordination of the protected alkenyl amine. Migratory insertion proceeds with the formation of an $\mathrm{Nil}($ alkyl)(sulfonamido) metallacycle. Subsequent transmetalation affords an Nill(alkyl)(aryl) species which would finally undergo reductive elimination to give the 1,2-diarylated product. It should be noted that this catalytic cycle may also operate with the sulfonamide directing group as an L-type ligand upon migratory insertion and this pathway cannot be ruled out at this time.

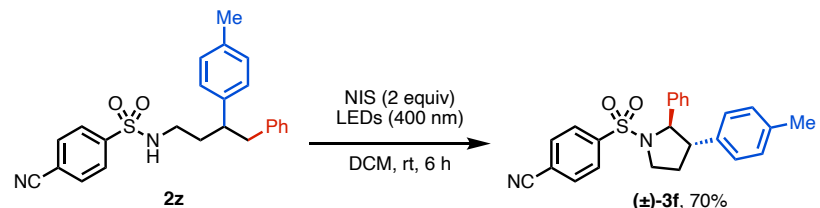

Scheme 4. HLF cyclization of a representative product.

We next envisioned that this method could have synthetic applicability as a linchpin technology where the diarylated products could engage in $\mathrm{N}$-functionalization followed by deprotection to form highly functionalized secondary amines that would otherwise be difficult to construct. The 4-cyano-phenyl sulfonyl (4-Cs) protecting group was utilized in scale-up and diversification efforts due to its precedented ease of removal by use of 1-dodecanethiol. ${ }^{[5]}$ With this in mind, we then synthesized diarylated product 2ai in $87 \%$ yield ( $1 \mathrm{mmol}, 0.40 \mathrm{~g}$ isolated) (Scheme 3 ). This product was then subjected to Mitsunobu coupling, propargylation, benzylation, $\mathrm{S}_{\mathrm{N}} \mathrm{Ar}$, and Boc protection reactions, which proceeded in moderate to good yields providing a diverse set of $\mathrm{N}$-functionalized products (3a-e). Subsequent treatment with 1-dodecanethiol and DBU led to the removal of the aryl sulfonyl protecting group affording dialkyl, alkyl propargyl, alkyl benzyl, alkyl aryl, and alkyl Bocprotected amines in low to excellent yields (4a-e). Lastly, a violet-light-initiated Hofmann-Löffler-Freytag (HLF) cyclization of a representative product, $\mathbf{2 z}$, furnished $4-\mathrm{Cs}$ protected pyrrolidine ( $\mathbf{\pm})$-3f in good yield, with the two aryl groups in a trans configuration (Scheme 4). ${ }^{[10]}$

In summary, a Ni-catalyzed 1,2-diarylation of aryl sulfonyl protected alkenyl amines with aryl iodides and aryl boronic esters was developed. This method tolerates electronically varied aryl coupling partners. Electronics on the aryl sulfonyl protecting group is indiscriminate of its directing capabilities with the exception of nosyl substitution. Internal and 1,1disubstituted alkenes are competent substrates, affording the desired products in moderate to high yields with excellent regio- and diastereoselectivity. Control experiments showed that the free sulfonamide $\mathrm{N}-\mathrm{H}$ is essential in the reaction. The alkenyl chain length was determined to tolerate dicarbofunctionalization with aryl sulfonyl protected allyl, butenyl, and pentenyl amines. Finally, this methodology may be implemented as a linchpin technology where aryl sulfonyl protected alkenyl amines could engage in 1,2-diarylation, then $\mathrm{N}$-functionalization, and lastly deprotection to afford trifunctionalized secondary amines allowing leeway for facile complex amine synthesis.

\section{Experimental Section}

General Procedure: To a 1-dram (4 mL) vial equipped with a Teflon-coated magnetic stir bar were added the alkene substrate $(0.1 \mathrm{mmol})$, the appropriate aryl boronic acid neopentylglycol ester $(0.3 \mathrm{mmol})$, the appropriate aryl iodide electrophile $(0.3 \mathrm{mmol})$, and dimethyl fumarate $(15 \mathrm{~mol} \%)$. The vial was then equipped with a septum cap, which was pierced by a 20-gauge needle and introduced into an argon-filled glovebox antechamber. Once transferred inside the glovebox anhydrous $\mathrm{NaOH}(0.3 \mathrm{mmol}), \mathrm{Ni}(\operatorname{cod})_{2}(20 \mathrm{~mol} \%)$, and anhydrous sec-butanol $(0.5 \mathrm{~mL})$ were added. After stirring for $30 \mathrm{sec}$, the vial was sealed with a screw-top cap, removed from the glovebox, and left to stir at room temperature for $12 \mathrm{~h}$. After this time, the reaction mixture was diluted with EtOAc $(1 \mathrm{~mL})$, poured into a test tube filled with satd. aq. $\mathrm{NaHCO}_{3}(10 \mathrm{~mL})$ rinsing with EtOAc $(1 \mathrm{~mL})$, and was extracted with EtOAc $(3 \times$ $1 \mathrm{~mL}$ ). The organic layers were combined, and the solvent was removed in vacuo to leave a yellow residue, which afforded pure product after preparative thin-layer chromatography (PTLC).

\section{Acknowledgements}

This work was financially supported by the National Science Foundation (CHE-1800280) and Bristol Myers Squibb. We acknowledge the NSF for Graduate Research Fellowships (DGE-1346837, J.D. and DGE-1842471, O.A.). We further thank Dr. Han Nguyen and Dr. Milan Gembicky for X-ray crystallographic analysis (UCSD). We thank Andrew M. Romine for detailed proofreading of this manuscript.

Keywords: alkene $\cdot$ diarylation $\cdot$ nickel $\cdot$ sulfonamide

[1] For representative reviews on conjunctive cross-coupling, see: (a) J Derosa, V. T. Tran, V. A. van der Puyl, K. M. Engle, Aldrichimica Acta 2018, 51, 21-32. (b) R. Giri, S. KC, J. Org. Chem. 2018, 83, 3013 3022. (c) J. Derosa, O. Apolinar, T. Kang, V. T. Tran; K. M. Engle Chem. Sci. 2020, 11, 4287-4296. (d) H.-Y. Tu, S. Zhu, F.-L. Qing, L. Chu, Synthesis 2020, 52, 1346-1356. (e) S. O. Badir, G. A. Molander, Chem 2020, 6, 1327-1339. (f) X. Qi, T. Diao, ACS Catal. 2020, DOI: 10.1021/acscatal.0c02115.

[2] (a) J.-W. Gu, Q.-Q. Min, L.-C. Yu, X. Zhang, Angew. Chem. Int. Ed. 2016, 55, 12270-12274; Angew. Chem. 2016, 128, 12458-12462. (b) C. Xu, Z.-F. Yang, L. An, X. Zhang, ACS Catal. 2019, 9, 8224 8229. (c) Z.-F. Yang, C. Xu, X. Zheng, X. Zhang, Chem. Commun. 2020, 56, 2642-2645. (d) B. Shrestha, P. Basnet, R. K. Dhungana, S. KC, S. Thapa, J. M. Sears, R. Giri, J. Am. Chem. Soc. 2017, 139, 10653-10656. (e) W. Li, J. K. Boon, Y. Zhao, Chem. Sci. 2018, 9, 600-607. (f) X. Wei, W. Shu, A. García-Domínguez, E. Merino, C. Nevado, J. Am. Chem Soc. 2020, DOI: 10.1021/jacs.0c05254

[3] (a) J. Derosa, R. Kleinmans, V. T. Tran, M. K. Karunananda, S. R. Wisniewski, M. D. Eastgate, K. M. Engle, J. Am. Chem. Soc. 2018 140, 17878-17883. (b) V. T. Tran, Z.-Q. Li, T. J. Gallagher, J. Derosa, P. Liu, K. M. Engle, Angew. Chem. Int. Ed. 2020, 59, 7029-7034; Angew. Chem. 2020, 132, 7095-7100. (c) For an example of sulfonamide-directed $C\left(\mathrm{sp}^{3}\right)-\mathrm{C}\left(\mathrm{sp}^{3}\right)$ cross-coupling, see: A. Wilsily, $\mathrm{F}$. Tramutola, N. A. Owston, G. C. Fu, J. Am. Chem. Soc. 2012, 134, 5794-5797.

[4] (a) J. Derosa, V. T. Tran, M. N. Boulous, J. S. Chen, K. M. Engle, J. Am. Chem. Soc. 2017, 139, 10657-10660. (b) J. Derosa, V. A. van der Puyl, V. T. Tran, M. Liu, K. M. Engle, Chem. Sci. 2018, 9, 52785283. (c) V. A. van der Puyl, J. Derosa, K. M. Engle, ACS Catal. 2019 9, 224-229. (d) R. Pan, C. Shi, D. Zhang, Y. Tian, S. Guo, H. Yao, A. Lin, Org. Lett. 2019, 21, 8915-8920. (e) P. Basnet, R. K. Dhungana, S. Thapa, B. Shrestha, S. KC, J. M. Sears, R. Giri, J. Am. Chem. Soc. 
2018, 140, 7782-7786. (f) P. Basnet, S. KC, R. K. Dhungana, B. Shrestha, T. J. Boyle, R. Giri, J. Am. Chem. Soc. 2018, 140, 1558615590. (g) R. K. Dhungana, S. KC, P. Basnet, V. Aryal, L. J. Chesley, R. Giri, ACS Catal. 2019, 9, 10887-10893. (h) X. Zhao, H.-Y. Tu, L. Guo, S. Zhu, F.-L. Qing, L. Chu, Nat. Commun. 2018, 9, 3488. (i) J. Derosa, T. Kang, V. T. Tran, S. R. Wisniewski, M. K. Karunananda, T. C. Jankins, K. L. Xu, K. M. Engle, Angew. Chem. Int. Ed. 2020, 59, 1201-1205; Angew. Chem. 2020, 132, 1217-1221. (j) L. Guo, H.-Y. Tu, S. Zhu, L. Chu, Org. Lett. 2019, 21, 4771-4776. (k) A. García-Domínguez, R. Mondal, C. Nevado, Angew. Chem. Int. Ed. 2019, 58, 12286-12290; Angew. Chem. 2019, 131, 1241412418. (I) T. Yang, X. Chen, W. Rao, M. J. Koh, Chem 2020, 6, 738751. (m) H.-Y. Tu, F. Wang, L. Huo, Y. Li, S. Zhu, X. Zhao, H. Li, F.L. Qing, L. Chu, J. Am. Chem. Soc. 2020, 142, 9604-9611.

[5] (a) M. A. Schmidt, R. W. Stokes, M. L. Davies, F. Roberts, J. Org. Chem. 2017, 82, 4550-4560. (b) T. Kan, T. Fukuyama. Chem. Commun. 2004, 353-359.

[6] For representative reviews on use of sulfonyl groups in organic synthesis, see: (a) K. Jarowicki, P. Kocienski, J. Chem. Soc., Perkin Trans. 1 1998, 4005-4037. (b) J. D. Wilden, J. Chem. Res. 2010, 34, 541-548.

[7] For examples of electron-deficient olefins as ligands in transition metal catalysis, see: (a) J. B. Johnson, T. Rovis, Angew. Chem., Int Ed. 2008, 47, 840-871; Angew. Chem. 2008, 120, 852-884. (b) A. E. Jensen, P. Knochel, J. Org. Chem. 2002, 67, 79-85. (c) C.-Y. Huang, A. G. Doyle, J. Am. Chem. Soc. 2015, 137, 5638-5641. (d) J. G. Estrada, W. L. Williams, S. I. Ting, A. G. Doyle, J. Am. Chem. Soc. 2020, 142, 8928-8937.

[8] R. S. Berman, J. K. Kochi, Inorg. Chem.1980,19, 248-254.

[9] R. T. McGuire, C. M. Simon, A. A. Yadav, M. J. Ferguson, M. Stradiotto, Angew. Chem. Int. Ed. 2020, 59, 8952-8956; Angew. Chem. 2020, 132, 9037-9041.

[10] C. Q. O’Broin, P. Fernández, C. Martínez, K. Muñiz, Org. Lett. 2016, 18, 436-439. 